\title{
Comunidade e escola: reflexões sobre uma integração necessária
}

\section{The school and the comumnity: reflections about a necessary integration}

\author{
Zedeki Fiel Bezerra ${ }^{1}$ \\ Fernanda Alves Sena ${ }^{2}$ \\ Osmarina Maria dos Santos Dantas ${ }^{3}$ \\ Alden Rodrigues Cavalcante ${ }^{4}$ \\ Luiza Nakayama ${ }^{5}$
}

1 Especialista em História da Amazônia pela Universidade da Amazônia (UNAMA). Professor da Secretaria de Educação do Pará (SEDUC/PA). Integrante do Grupo de Pesquisas e Estudos em Educação Ambiental (GPEEA)-Sala Verde Pororoca-Núcleo Pedagógico de Apoio ao Desenvolvimento Científico (NPADC) da Universidade Federal do Pará, Brasil. E-mail: zedeki@ ig.com.br.

2 Graduada em Pedagogia pela Universidade Estadual do Pará, Brasil. Integrante do Grupo de Pesquisas e Estudos em Educação Ambiental (GPEEA)-Sala Verde Pororoca-Núcleo Pedagógico de Apoio ao Desenvolvimento Científico (NPADC) da Universidade Federal do Pará, Brasil. E-mail: fasena1@hotmail.com.

3 Mestrado em Educação em Ciências e Matemáticas pelo Programa de Pós-Graduação em Educação em Ciências e Matemáticas (PPGECM), Núcleo Pedagógico de Apoio ao Desenvolvimento Científico (NPADC) da Universidade Federal do Pará, Brasil. Integrante do Grupo de Pesquisas e Estudos em Educação Ambiental (GPEEA)-Sala Verde Pororoca-Núcleo Pedagógico de Apoio ao Desenvolvimento Científico (NPADC) da Universidade Federal do Pará, Brasil. E-mail: osmarinamaria@yahoo.com.br.

4 Licenciado Pleno em História e Bacharel em Psicologia - Faculdades Integradas do Colégio Moderno (Ficom). Professor da Secretaria de Educação do Pará (SEDUC/PA). Integrante do Grupo de Pesquisas e Estudos em Educação Ambiental (GPEEA)-Sala Verde Pororoca-Núcleo Pedagógico de Apoio ao Desenvolvimento Científico (NPADC) da Universidade Federal do Pará, Brasil. E-mail: cavalcantealden@yahoo.com.br.

5 Doutora em Genética Bioquímica e Molecular, Núcleo Pedagógico de Apoio ao Desenvolvimento Científico (NPADC) da Universidade Federal do Pará, Brasil. Professora do Programa de Pós-Graduação em Educação em Ciências e Matemáticas (PPGECM), Núcleo Pedagógico de Apoio ao Desenvolvimento Científico (NPADC) da Universidade Federal do Pará, Brasil. Coordenadora do Grupo de Pesquisas e Estudos em Educação Ambiental/Sala Verde Pororoca e professora orientadora no Projeto Clube de Ciência da Universidade Federal do Pará (CCIUFPA), Brasil. E-mail: lunaka@ufpa.br, sverdepororoca@ufpa.br. 


\title{
André Ribeiro de Santana ${ }^{6}$
}

\begin{abstract}
RESUMO
Este estudo apresenta reflexões acerca do estabelecimento de parceria entre a escola e a sua comunidade. Com o objetivo de avaliar essa parceria, efetivamos pesquisas em uma escola pública e outra conveniada, utilizando questionários e entrevistas. As respostas dos alunos e membros da comunidade evidenciaram diferenças de posicionamentos. Por exemplo: na escola pública houve queixas de ausência de interações o que resultou em sentimentos de não pertencimento e indiferença; já na escola conveniada a comunidade sente-se responsável pela escola, graças principalmente às oportunidades de interações estabelecidas. Concluímos que a comunidade reconhece a importância de se envolver nas ações escolares, cabendo a escola viabilizar esse acesso, estruturando um ensino efetivamente significativo.

Palavras-chave: escola; comunidade; educação; parceria.
\end{abstract}

\begin{abstract}
This study presents reflections regarding the establishment of a partnership between the school and its community. With the objective of evaluating such partnership, researches were carried out in a public school and other in agreement, using questionnaires and interviews. The answers from the students and community members indicated different positions. For example: in the public school there were complains about the absence of interaction which led to a sensation of not belonging and indifference. On the other hand, in the university partnership school the community feels responsible for the school, thanks mainly to the possibilities of interaction that have been established. We have reached the conclusion that the community recognizes the importance of becoming involved in school actions, being school's responsibility to provide such access, by structuralizing an effectively significant teaching.
\end{abstract}

Keywords: school; community; education; partnership.

6 Mestre em Educação em Ciências e Matemáticas pelo Núcleo Pedagógico de Apoio ao Desenvolvimento Científico (NPADC) da Universidade Federal do Pará, Brasil, professor da Secretaria de Educação do Pará (SEDUC/PA), membro do Grupo de Pesquisas e Estudos em Educação Ambiental (GPEEA)/Sala Verde Pororoca, Brasil. E-mail: mestredeo@yahoo.com.br. 


\section{Introdução}

A escola pública tem como compromisso oportunizar condições para sua clientela construir conhecimentos, atitudes e valores, contribuindo na formação de cidadãos críticos, éticos e participativos nos contextos que integram (BRASIL, 2004). No entanto, que requer superação de obstáculos, pois segundo Atié (1999, p. 3), em sua análise sobre a escola pública: "Hoje, o desafio que se coloca diante da escola é fornecer educação e informação para toda a vida... ela precisa romper seus muros e estar plenamente inserida no seu tempo e na comunidade a qual pertence.”

Ações escolares devem ser consolidadas em um contexto participativo, integrador de todos seus segmentos, sincronizadas com o contexto atual, que requer uma política educacional capaz de contribuir na condução do país ao pleno desenvolvimento, em conformidade com os princípios democráticos em evolução.

Mais de vinte anos se passaram desde o término da ditadura militar, e o povo brasileiro vem reconquistando sua atuação nas decisões políticas, portanto, a escola deve investir em projetos político-pedagógicos que contribuam com a ação cidadã consciente e responsável. Esse pressuposto é reforçado por Freire (2005, p. 79), o qual enfatiza que contextos não são imutáveis.

Não se trata obviamente de impor à população espoliada e sofrida que se rebele, que se mobilize, que se organize para defender-se, vale dizer, para mudar o mundo. Trata-se na verdade - não importa se trabalhamos com alfabetização, com saúde, com evangelização ou com todas elas -, de, simultaneamente com o trabalho específico de cada um desses campos, desafiar os grupos populares para que percebam, em termos críticos a violência e a profunda injustiça que caracterizam a sua situação concreta. Mais ainda, que sua situação concreta não é destino certo ou vontade de Deus, algo que não pode ser mudado.

Certamente a escola, nicho tradicional de socialização de conhecimentos (NOGUEIRA, 1999) é espaço privilegiado para efetivações de mudanças, ao envolver a comunidade ${ }^{7}$ nas questões educacionais.

7 O sentido de comunidade presente neste trabalho é o de Cody; Siqueira (1997). Para esses autores, por comunidade do entorno da escola, devem-se entender os pais, os professores e os representantes do meio econômico, político e social, na qual a escola está inserida. 
Para nortear nosso estudo levantamos a seguinte indagação: como está a relação da escola com a comunidade assistida?

Através do estudo da relação escola-comunidade também poderemos discutir indagações acerca:

Da formação para a cidadania, da possibilidade de promover uma educação mais significativa na escola, da solução de problemas de violência e vandalismo nas unidades escolares, da permanência das crianças na escola, das questões sobre a relação entre educação e trabalho... (NOGUEIRA, 1999, p. 14).

Na introdução dos Parâmetros Curriculares Nacionais (PCNs), é abordada a relevância em:

[...] mostrar a importância da participação da comunidade na escola, de forma que o conhecimento apreendido gere maior compreensão, integração e inserção do mundo; a prática escolar comprometida com a interdependência escola-sociedade tem como objetivo situar as pessoas como participantes da sociedade - cidadãos - desde o primeiro dia de sua escolaridade. (BRASIL, 1998, p. 10).

Para concretizar esse intento, é imprescindível que ocorra integração entre a escola e a comunidade atendida, com reconhecimento e valoração dos saberes extracurriculares e efetivação de parcerias no trabalho educativo, atingindo o maior contingente de pessoas em sua área de localização. Devemos considerar que todos os participantes do processo educativo têm a capacidade de elaboração propostas para a melhoria da educação.

Esse processo de interação deve ser pautado no diálogo e na confiança. Para isso a escola deve oportunizar "situações de encontro" a fim de conhecer os recursos da comunidade e os aspectos da sua realidade, visando à melhoria do ensino-aprendizagem. 


\section{Material e métodos}

Para analisar o envolvimento das escolas com a comunidade do seu entorno, efetivamos observações in loco, entrevistas semiestruturadas e aplicação de questionários em duas escolas da região metropolitana de Belém - PA, ambas atendendo predominantemente, indivíduos de baixo nível socioeconômico.

Os questionários continham quatro questões abertas relacionadas com a investigação: como está a relação da escola com a comunidade assistida? Para salvaguardar sua privacidade, os alunos foram denominados de A e os pais foram referidos como $P$.

Um dos estabelecimentos investigados pertence à rede pública de ensino, situando-se em um bairro economicamente carente, com problemas cotidianos de violência urbana. A instituição oferta nos turnos da manhã e tarde o Ensino Fundamental e no turno da noite, o Ensino Médio, possuindo mais de dez salas de aula, área de merenda e recreação, quadra polivalente, além de uma pequena biblioteca.

A outra escola investigada situa-se em um bairro de classe média. Trata-se de instituição privada sem fins lucrativos, mantida pela Congregação das Irmãs Salesianas dos Sagrados Corações. Seu funcionamento é garantido a partir de convênio com a Secretaria Executiva de Educação, responsável pela totalidade de seu quadro técnico, docente e de apoio. No Ensino Fundamental, atende especificamente alunos portadores de deficiência auditiva.

A Instituição dispõe de 15 salas de aula, auditório, quadra poliesportiva, piscina semiolímpica, laboratório de informática educativa, sala de leitura, brinquedoteca, gabinete médico-odontológico e sala para atendimento social e psicológico. Também apresenta ambientes específicos para atendimento aos portadores de deficiências auditivas, como sala de ritmos fonéticos, sala de estimulação multisensorial e consultório de fonoaudiologia.

\section{Resultados e discussões}

Na escola pública a pesquisa foi desenvolvida com a participação de cinco alunos - três do sexo masculino - do terceiro ano do Ensino Médio e pais da comunidade do entorno, convidados pelos primeiros, a nosso pedido. Em relação à faixa etária, os alunos situam-se entre 18 e 25 anos; os pais entrevis- 
tados são bastante jovens com idade entre 20 e 25 anos $^{8}$. Todos os sujeitos são trabalhadores com renda média entre um a dois salários mínimos. Os alunos foram denominados de A1, A2, A3, A4 e A5; os pais, todos do sexo masculino, foram referidos como P1, P2, P3 e P4.

$\mathrm{Na}$ escola conveniada foram entrevistados cinco pais e seis alunos, os procedimentos, dada a especificidade da clientela, incluíram entrevistas em libras ${ }^{9}$. Os pais foram denominados: de P5, P6, P7, P8 e P9; os alunos de A6, A7, A8, A9, A10 e A11.

Em vista da especificidade das duas escolas, preferimos avaliá-las separadamente nos dois tópicos a seguir:

\section{Olhares para uma escola pública}

Um dos autores deste artigo, Zedeki Fiel Bezerra, atuou como professor nessa escola pública. A partir de suas vivências constatou que os nossos entrevistados se sentem intimidados pelo corpo docente-administrativo, devido à percepção da escola como concessão do poder público, relacionada a fatores como: 1) baixa posição socioeconômica, consequência da nula ou mínima escolarização dos pais ou responsáveis e 2) impossibilidade financeira dos pais para matricular os filhos em escolas particulares.

Essa realidade promove em nossos sujeitos o comportamento apontado por Pereira (1976, p. 129): “Eles sabem, por experiência própria, da posição desvantajosa em que ficam as pessoas que não dominam suficientemente as 'técnicas elementares da cultura', num ambiente cuja cultura apresenta amplos setores letrados".

Constatamos que a escola não conta com organizações favorecedoras de integração comunitária, tais como Associação de Pais e Mestres (APM), Grêmio Estudantil, importantes instrumentos para a iniciação e formação democrática, com papel relevante na garantia do entrosamento entre escola e comunidade.

8 No estabelecimento pesquisado é comum estudarem pais e filhos, geralmente em turnos diferentes. Como o autor Zedeki Fiel Bezerra não gostaria de ter o mesmo sujeito em categorias simultâneas, os pais entrevistados não pertencem à turma dos que foram categorizados como alunos.

9 Libras é sigla para Língua Brasileira de Sinais. As línguas de sinais são consideradas como um legítimo sistema linguístico, influenciadas por fatores geográficos e culturais, portanto inexiste uma língua de sinais universal, mas diversas, conforme as peculiaridades de cada país. (QUADROS; KARNOPP, 2004) 
O Conselho Escolar existe, porém, funciona de forma deficitária, sem a participação maciça da comunidade intra e extraescolar. Trata-se de um dado relevante, pois, esse órgão é responsável pelo gerenciamento e fiscalização das verbas federais destinadas às escolas.

Esse quadro situacional pode responder pelos danos no patrimônio da escola, como por exemplo, salas pichadas, carteiras e banheiros depredados, etc. Além disso, não raro, alunos agridem verbal e fisicamente seus professores, o pessoal de apoio e os próprios colegas, em uma demonstração explícita de desrespeito a escola como um todo.

Em relação a essa questão específica percebemos posicionamentos contraditórios: os próprios alunos rogam por uma maior disciplina na escola, porque acreditam seja essa uma das formas de combater a violência interna e de se construir respeito pela escola. Porém, também percebemos atitudes de apatia e desinteresse entre os discentes, através de falas como "só quero meu diploma e pronto" ou "essa escola não ta [sic] com nada".

Quanto à percepção de interações com a comunidade, os depoimentos confirmaram as impressões já descritas acerca da escola: "Pra ser sincero, aqui não existe não. A gente não vê a escola fazer alguma coisa para chamar a comunidade para a escola." (A1).

O posicionamento do Aluno A2 é bem mais detalhado:

- Na escola não podemos afirmar que há uma completa interação entre todos os membros da comunidade. Podemos dizer que há diretamente uma interação entre professores e alunos e diretor. Os pais e o resto da comunidade escolar participam como expectadores e tem acesso somente aos serviços burocráticos (boletim, requerimentos, etc.). Não há uma interação completa de fato.

Preocupações com um planejamento que considere necessidades e anseios da comunidade fizeram-se notar nos depoimentos. Obtivemos as seguintes considerações: "As escolas planejam suas ações sem considerar as necessidades da comunidade. Isso reflete na qualidade do ensino, tornando deficiente o nível educacional.” (A2).

Esse posicionamento é reforçado pelo depoimento do informante P2: "Se a escola planejasse suas ações com a comunidade tudo seria bem melhor. Ex. A comunidade precisa dar suas opiniões, a escola precisava promover palestras de como agir e se ajudarem." 
No que concerne a necessidade da interação escola e comunidade, como forma de otimizar bons resultados no processo educativo, nossos informantes julgaram relevante tal engajamento: "A comunidade não só deve partilhar como também opinar, construir ideias, montar projetos, pois além de ser uma obrigação, todos vão poder conhecer, interagir, respeitar e colocar inúmeras observações e respostas para seus questionamentos” (A2).

Para o informante P1: "Muitas pessoas nem fazem ideia dos direitos e deveres que têm com a sua comunidade, essa, com certeza, deve sim participar e contribuir para a melhoria do nosso ensino".

O informante A5 complementa: "Uma vida participativa torna mais fácil a comunicação entre as pessoas da comunidade e também entre pais e filhos que acabam ajudando uns aos outros”.

Desse modo, percebe-se que a comunidade acredita ter como "... atuar no processo educativo de modo ativo e frequente" (VIANNA, 1986, p. 84), ressentindo-se da ausência de estratégias, por parte da escola, para envolvê-la em seu planejamento e, também, entende que por falta dessa participação a educação de seus filhos fica prejudicada.

As razões dessa interação pouco proveitosa foram referidas. Por exemplo: Para o informante P3 ambos os lados têm sua parcela de responsabilidade: "Falta convite e incentivo da parte da escola, falta conhecimento, interesse e costume por parte da comunidade em ajudar no dia a dia da escola".

Disponibilidade de tempo e baixos níveis de escolarização também são considerados entraves para maior participação no cotidiano escolar: "A dificuldade é que a maioria trabalha, outros não têm leitura, falta informação e disponibilidade" (P4).

Diante da entrevista ${ }^{10}$, os alunos, talvez por se sentirem livres da obrigação de escrever suas respostas, aprofundaram ainda mais as suas reflexões e críticas com relação à escola. Reclamaram da ausência dos professores de determinadas disciplinas e da falta de explicações para esse fato, por parte da administração da escola.

Para nosso informante A1, a escola tem falhado em dois aspectos primordiais: "O primeiro é o respeito que a escola não tem com a sua comunidade. O segundo é o diálogo que a escola não tem com a comunidade, dessa forma como é que ela pode participar da vida da escola?”.

Em suas falas apontam que "falta muita coisa" (A4), para a melhoria da escola. Reclamam da "falta de disponibilidade" (A5) do corpo administrativo em tratar de assuntos de seus interesses. Também se queixaram que quando

10 Como alguns dos indivíduos que concordaram em depor alegaram não estar acostumados a responder por escrito, optamos por complementar a pesquisa com entrevistas. 
precisam realizar pesquisas: "fazem em outras escolas ou outros locais, pois a biblioteca permanece fechada na maior parte do turno da noite" (A3).

Esses argumentos apresentados pelos alunos e/ou responsáveis estão de acordo com as constatações iniciais do primeiro autor. Diante do quadro apresentado depreende-se que o distanciamento entre a escola e a comunidade reflete negativamente nos processos de ensino e aprendizagem como citado em Brasil (1998) e como argumenta Cody e Siqueira (1997):

É preciso participar da vida escolar dos filhos e da escola. A contínua colaboração entre escola e os pais faz com que se tornem parceiros no processo educacional. A falta de comunicação entre a escola e os pais leva ao comprometimento do sucesso escolar (CODY; SIQUEIRA, 1997, p. 15).

Logo, concluímos que é de extrema importância que a escola, ao planejar e programar suas ações pedagógicas procure envolver sua comunidade na construção do conhecimento.

Ao inquirirmos nossos informantes sobre como efetivar essa aproximação, a sugestão foi unânime: abertura da escola nos finais de semana, para utilização da quadra esportiva e da biblioteca pelos moradores do bairro, os quais poderiam praticar esportes, organizar festivais e gincanas culturais, ler e/ou estudar. Essa resposta nos levou a indagar como fariam para concretizar essa proposta. O informante (A3) sintetizou o pensamento coletivo: "A gente vai ter que conversar com a escola”.

Mas, para que haja a participação coletiva, é fundamental o estabelecimento de regras claras referentes à sua concretização. Também é necessário que sejam respeitadas as individualidades dos envolvidos, afinal irão responder diretamente pela contribuição propriamente dita. Assim, Szymanski (2001) e Padilha (2006) consideram que setores escolares e comunitários podem unir forças e atuar em todas as instâncias - financeira, pedagógica, administrativa diálogo, responsabilidade e transparência revelam-se fundamentais para o bom encaminhamento e manutenção das ações.

Por não viverem a escola, não se sentirem inseridos nem pertencentes à mesma, os alunos e demais elementos da comunidade não conseguem criar um sentimento de valorização, nem assimilam a importância da escola em suas vidas. Felizmente, apesar de vivenciarem um contexto pouco favorável com a escola, percebemos nas falas de nossos informantes, interesse genuíno em dialogar acerca de interações mais produtivas. 


\section{Uma situação de parceria em uma escola conveniada}

Em um panorama onde a relação escola e comunidade nem sempre é de plena interação, é interessante destacar ações que procuram estimular a participação de todos em seu cotidiano.

O projeto político-pedagógico contempla periodicamente sua comunidade com cursos e palestras relacionadas à inclusão - escolar e social. A relevância dessas ações é atestada por depoimentos como estes: "Eu sinto que esta escola ajuda meus filhos, passa valores morais, se preocupa com o futuro deles" (P9). "Se não fosse esta escola o meu filho nem tivesse [Sic] estudando e recebesse o que recebe de educação" (P8). Essas opiniões são compartilhadas pelos alunos. Por exemplo, para o informante A6: “... a escola boa, ajudar viver bem, igual casa" e para o A9 entende que: “... precisar escola vida boa."11.

Os pais e responsáveis respondem com frequência quando são chamadas a participar de reuniões pedagógicas, como os Conselhos de Classe realizados semestralmente e em atividades para angariar recursos para a escola - bazares, feiras de pechincha, festas promocionais - além da organização de peças teatrais nas dependências da escola. Para o informante P6: "A gente se sente parte da escola, quando se envolve com certas atividades aqui dentro." Igualmente enfático é o posicionamento do informante P5: "Acho importante colaborar com a escola, ajudar quando ela precisa na copa, na limpeza e nos eventos. Porque assim estou ajudando também meu filho".

Como a maioria dos pais e alunos aprecia participar das atividades de sala de aula e de eventos extraclasse veem a escola como a "continuação do seu lar", procurando zelar pelo patrimônio físico, conforme sintetiza a fala de A11: "Sujar escola não, bonita limpa". Essa constatação nos remete as ponderações de Szymanski (2001) acerca da aprendizagem escolar, que não precisa se restringir aos conteúdos programáticos, pois através das vivências no cotidiano da escola também se aprimoram apreços, posturas de vida e sensibilidades.

Evidentemente o agir docente é fundamental nesse contexto diferenciado. De modo geral, os professores lotados na escola conveniada atuam na construção, execução e manutenção dos projetos escolares, procurando contribuir para o pleno desenvolvimento dos seus assistidos, transcendendo o processo ensinoaprendizagem focado no mero repasse de conteúdos programáticos.

11 O portador de deficiência auditiva comunica-se empregando as línguas de sinais. No Brasil temos a Linguagem Brasileira de Sinais-Libras Ao expressarem-se em língua portuguesa não utilizam elementos de ligação, tais como conjunções e preposições, pois estes não fazem parte de sua linguagem usual. (QUADROS; KARNOPP, 2004) 
Carvalho (2003) acredita que a ressignificação de relações requer atenção a diversos fatores, como mudanças paradigmáticas: do ensino expositivo focado na competência docente passando para o ensino focado na construção de conhecimentos pelo aluno e, de acordo com Szymanski (2001), em um panorama no qual a importância das contribuições da comunidade tem sido alvo de considerações. Paralelamente as essas mudanças há necessidade de acompanhamento, afinal todo processo requer, acima de tudo, persistência; seja para resistir ao impulso de repetir hábitos arraigados, seja para efetivar novos procedimentos (NOGUEIRA, 1999). Essa condução pode ser efetivada mediante as considerações de Buffa et al. (2000) ou seja: democraticamente concretizada pelo agir coletivo dos vários segmentos que compõem a escola, respeitando as características e competências de cada grupo.

Na sua busca pela cooptação da comunidade nas suas ações, conclui-se que os desafios são vivenciados diariamente pela escola conveniada. O resultado desse empenho é a produção de um ensino significativo, para uma comunidade cuja consciência em participar da Educação aumenta gradativamente.

\section{Considerações finais}

Esse estudo identificou a importância da escola ver a si mesma como parte integrante da comunidade, e, reciprocamente, dessa reconhecer a escola como uma instituição sua, da qual pode participar e cuidar.

As ações escolares restringem-se a procedimentos administrativos e pedagógicos, encaminhados pela direção e pelos corpos técnico e docente, sem maiores interações com os alunos e a comunidade, os quais figuram apenas como peças obrigatórias ao funcionamento escolar que não conta com espaços de congregação comunitária como a APM e Conselho Escolar, que não atua com plenitude.

Entendemos que a instituição responsável pela escola pública deveria dispensar maior atenção às unidades sob sua responsabilidade, implementando ações para modificar o quadro situacional relatado pelos nossos informantes.

A escola conveniada, por sua vez, revelou-se como unidade aberta à sua comunidade: busca sistematicamente construir um processo de educação que considere a diferença relacionada à especificidade dos seus alunos atendidos, as necessidades e os anseios dos que ela assiste, visando realizar uma educação de qualidade direcionada para a realidade e para a superação dos problemas sociais presentes em nossa sociedade. É importante ressaltar que o envolvimento ob- 
servado na escola conveniada também advém da filosofia de trabalho específica da congregação filantrópica mantenedora.

É evidente que toda a infraestrutura de uma instituição é um fator muito importante, mas consideramos que as diferenças de postura e de vivências fazem com que os alunos e a comunidade percebam a escola de modo diferenciado.

As situações apresentadas nos levam a crer na necessidade de modificar as relações no cotidiano escolar, incentivando novos olhares para a educação, identificando necessidades, buscando ofertar um ensino significativo para a comunidade, afinal a escola precisa sempre atentar ao desenvolvimento integral dos alunos, em um mundo em constante mudança.

Entendemos que encontrar o caminho para relações de parceria pode ser uma experiência significativa, resultando em melhorias nas interações humanas, no ensino, na preservação das instalações físicas e combate da violência dentro e fora da escola. Pode ser a luz de um novo tempo na educação: o aproveitamento das experiências familiares na construção do saber e das ações da escola.

\section{REFERÊNCIAS}

ATIÉ, Lourdes. Editorial. Pátio-Revista Pedagógica, Porto Alegre, ano 3, n. 10, p. 3, ago/out, 1999.

BRASIL. Parâmetros Curriculares Nacionais ( $5^{a} a 8^{a}$ Série): Introdução aos Parâmetros Curriculares Nacionais. Brasília. MEC/SEF, 1998.

BRASIL. Ministério da Educação. Secretaria de Educação Básica. Caderno 1 Conselhos Escolares: democratização da escola e construção da cidadania. Brasília - DF, 2004 Disponível em: <http://portal.mec.gov.br/seb/arquivos/pdf/Consescol/ ce_cad1.pdf $>$ Acesso em: 8/8/2008.

BUFFA, Ester; ARROYO, Miguel; NOSELLA, Paolo. Educação e cidadania: quem educa o cidadão? São Paulo: Cortez, 2000. (Coleção questões da nossa época; v. 19).

CARVALHO, Anna Maria Pessoa de. (Coord.). Formação continuada de professores: uma releitura das áreas de conteúdo. São Paulo: Pioneira Thomson Learning, 2003.

CODY, Frank; SIQUEIRA, Silvia. Escola e Comunidade: Uma parceria necessária. São Paulo: IBIS, 1997.

FREIRE, Paulo. Pedagogia da Autonomia: saberes necessários à prática educativa. São Paulo: Paz e Terra, 2005. 
FREIRE, Paulo (Org.). Fazer Escola Conhecendo a Vida. Campinas: Papirus, 1990.

NOGUEIRA, Neide. A relação entre escola e comunidade na perspectiva dos Parâmetros Curriculares Nacionais. Pátio-Revista Pedagógica, Porto Alegre, ano 3, n. 10, p. 1317, ago/out, 1999.

PADILHA, Paulo Roberto. Planejamento dialógico: como construir o projeto políticopedagógico da escola. São Paulo: Cortez; Instituto Paulo Freire, 2006 (Guia da escola cidadã).

PEREIRA, Luiz. A Escola numa área metropolitana: crise e racionalização de uma empresa pública de serviços. São Paulo: Pioneira, 1976.

QUADROS, Ronice Muller de; KARNOPP, Lodenir Becker . Língua Brasileira de Sinais: estudos línguísticos. Porto Alegre: Artmed, 2004.

SILVA, Aida Maria Monteiro. Escola pública e a formação da cidadania: possibilidades e limites. 222f. Tese (Doutorado em Educação) - Faculdade de Educação, Universidade de São Paulo, São Paulo, 2000.

SZYMANSKI, Heloisa. A relação família/escola: desafios e perspectivas. Brasília: Plano Editora, 2001.

VIANNA, Ilca Oliveira de Almeida. Planejamento Participativo na Escola: um desafio ao educador. São Paulo: EPU, 1986.

Texto recebido em 24 de outubro de 2008.

Texto aprovado em 15 de dezembro de 2008. 
